\title{
The use of donor-derived veto cells in hematopoietic stem cell transplantation
}

\section{Eran Ophir and Yair Reisner*}

Department of Immunology, Weizmann Institute of Science, Rehovot, Israel

Edited by:

Eliane Gluckman, eurocord, France

\section{Reviewed by:}

Joerg Halter, University Hospital

Basel, Switzerland

Reem Al-Daccak, Institut National de

la Santé et de la Recherche Médicale, France

\section{*Correspondence:}

Yair Reisner, Department of

Immunology, Weizmann Institute of

Science, Herzl 1, POB 26, Rehovot

76100, Israel. e-mail:

yair.reisner@weizmann.ac.il
The induction of immune tolerance by specific agents, as opposed to general immune suppression, is a most desirable goal in transplantation biology. One approach to attain this goal is afforded by the use of donor-derived cells endowed with veto activity, which is the ability of a cell to specifically suppress only $T$ cells directed against its antigens. A megadose of purified veto $\mathrm{CD}_{3}{ }^{+}$hematopoietic stem cells is already used in patients to allow hematopoietic stem cells transplantation (HSCT) across major genetic barriers, while avoiding severe graft versus host disease (GVHD). However, allowing engraftment of such T cell-depleted HSCT under safer reduced intensity conditioning (RIC) protocols still remains a challenge. Therefore, combining megadose of $\mathrm{CD} 34^{+} \mathrm{HSCT}$ with other GVHDdepleted veto cells could enable facilitation of engraftment of HSCT under RIC without the adverse complication of GVHD. This approach might provide a safer modality for enabling engraftment of HSCT, enabling its application in elderly patients who cannot tolerate intensive protocols and to a variety of patients with non-malignant disorders, associated with longer life expectancy, in whom the use of a high risk conditioning cannot be considered.

Keywords: veto, hematopoietic stem cell transplantation, megadose, $\mathrm{CD}_{34}{ }^{+}$cells, anti-third-party $\mathrm{CD}^{+} \mathrm{Tcm}^{-}$

\section{INTRODUCTION}

Hematopoietic stem cell transplantation (HSCT) has become a common procedure of therapy for patients with hematological malignancies and many other life threatening blood disorders. However, viral and fungal infections associated with the severe immunoablative conditioning used prior to HSCT still represent a major challenge (Martelli etal., 2002; Seggewiss and Einsele, 2010). One approach to address this barrier is to use reduced intensity conditioning (RIC). HSCT following RIC relies on nonmyeloablative preparatory regimen that spares a substantial level of the host immunity and thus reduce transplant related mortality (TRM) by both improving post-transplant immune reconstitution and reducing the toxicity associated with the conditioning agents (Ballen and Spitzer, 2010; Gyurkocza et al., 2010). RIC was first developed to enable allogeneic HSCT in patients with advanced hematological malignancies who cannot withstand myeloablative conditioning because of age and/or performance status. However, using such "safer" RIC protocols also enable the use of HSCT in patients with non-malignant disorders, associated with longer life expectancy. In these patients the aim of the conditioning prior to the allogeneic HSCT is merely to support sustained donor cell's engraftment for correction of the disease (Steward and Jarisch, 2005; Ringden et al., 2006), or, as demonstrated in limited number of patients, for the induction of donor chimerism, as a platform for tolerance induction as prelude to organ transplantation (Kawai et al., 2008; Scandling et al., 2008). Nevertheless, currently used RIC protocols are still relatively aggressive and therefore it is highly desirable to develop "safer" preparative regimen protocols that selectively achieve a state of donor-specific unresponsiveness without compromising the overall immune response.

\section{THE VETO CONCEPT}

One way to achieve a state of donor-specific tolerance uses donor cells endowed with veto activity. The term "veto," coined in 1980 by Miller (Miller, 1980), relates to the ability of cells to specifically delete $\mathrm{T}$ cells directed against antigens (Ags) of the veto cells themselves, but not against third-party Ag (Muraoka and Miller, 1983; Claesson and Miller, 1984). The suppression of effector $\mathrm{T}$ cells directed against the veto cells is both Ag-specific and major histocompatibility complex (MHC) restricted, resulting from the unique manner by which the veto cell kills its target. Thus, veto activity results from unidirectional recognition of the veto cell by the responding $\mathrm{T}$ cell, but not vice versa. Therefore, the recognizing $\mathrm{T}$ cell, the T cell receptor (TCR) of which is directed against the MHC of the veto cell, is killed upon binding to its veto target, due to exchange of signals allowed following this interaction. Hence, the use of donor veto cells capable of specifically eliminating only the host anti-donor $\mathrm{T}$ cell clones that mediate the transplant rejection while sparing other $T$ cells that can persist and fight infectious pathogens, could offer an effective modality for the induction of transplantation tolerance.

\section{VETO ACTIVITY OF BONE-MARROW CELLS}

Initially, veto activity was described for cells within the spleen of athymic nude mice (Miller, 1980). Based on this initial observation, various cell types have been shown to mediate veto activity including $\mathrm{T}$ lymphocytes, natural killer cells, and dendritic cells. A very strong veto activity was documented for $\mathrm{CD} 8^{+}$cytotoxic T cell (CTL) lines or clones (Fink et al., 1984; Claesson and Ropke, 1986; Claesson and Miller, 1989) and direct comparison of the veto reactivity of various cell types revealed that CTLs have the strongest in vitro veto effect (Reich-Zeliger et al., 2004a). 
In the context of bone-marrow transplantation (BMT), cells in murine BM and in T cell colonies grown from such BM were shown to mediate veto activity in vitro (Muraoka and Miller, 1980) and un-separated donor BM was shown to specifically reduce the frequency of anti-donor CTLs in grafted mice (Wood et al., 1992). However, this in vivo tolerizing activity of the BM cells could be attributed to $\mathrm{T}$ cells which reside within the BM. These T cells, while potentially mediating beneficial veto activity, also cause a severe multi-system graft versus host disease (GVHD). Early attempts to avoid GVHD risk and to apply T cell-depleted BMT (TDBMT) in leukemia patients indeed revealed that this benefit of GVHD prevention is offset by increased risk for graft rejection, due to absence of donor T cells within the graft (Gale and Reisner, 1986; Kernan et al., 1987).

However, veto activity could be also assigned to non-T cells within the BM. For example, a series of studies by the group of Judy Thomas described potent veto activity of cells within the $\mathrm{CD}^{+} \mathrm{CD}^{+} 6^{+} \mathrm{DR}^{-}$subset in the $\mathrm{BM}$ of rhesus macaque primates (Thomas et al., 1991; Asiedu et al., 1999). CD8 surface expression was shown to play a pivotal role in the tolerogenic effect of these BM cells. Thus, these studies demonstrated that CD8 crosslinking following interaction with donor-reactive CTL precursors (CTLp), elicits upregulation of transforming growth factor- $\beta 1$ (TGF- $\beta 1$ ) and Fas ligand (FasL) by these donor BM cells, leading to clonal deletion of the donor-reactive CTLp (Asiedu et al., 1999; Clement et al., 2002).

Another example of marked clinical relevance is the demonstration by Rachamim et al. (1998) that human hematopoietic CD34 ${ }^{+}$ progenitors are endowed with marked veto activity (Figure 1). Explaining in part how "megadose" of purified $\mathrm{CD} 34^{+}$cells enables to overcome rejection in recipients of three HLA-loci mismatched (haploidentical) HSCT while avoiding the threat of GVHD (Aversa et al., 1994, 2005; Reisner and Martelli, 1995). Interestingly, Gur et al. (2005) demonstrated that this veto activity is mediated through a TNF- $\alpha$ based mechanism. In addition, Gur etal. (2002) demonstrated that veto activity is not only mediated directly by the infused CD34+ ${ }^{+}$cells but also by their $\mathrm{CD}_{3}{ }^{+}$progeny, which lose this tolerizing activity upon completion of maturation, at the level of $\mathrm{CD}_{14}{ }^{+}$monocytes or $\mathrm{CD}^{+}{ }^{+}$neutrophils. Furthermore, preliminary results suggest that BM-derived immature dendritic cells, previously shown to induce immune tolerance, exhibit marked veto activity on CD8 $\mathrm{T}$ cells, in addition to the non-specific suppression of CD4 T cells mediated by the NO system (Zangi et al., 2009). Finally, NK cells which were shown to exhibit veto activity upon activation with IL-2, develop and appear early during the post-transplant period (Chrobak and Gress, 2001; Reich-Zeliger et al., 2004a).

Thus, based on these observations, the following working hypothesis can be suggested to explain how megadose of CD34 ${ }^{+}$ cells can overcome rejection in human recipients of haploidentical HSCT. Upon administration of purified CD34 ${ }^{+}$cells, the graft supporting veto activity is initially mediated directly by the infused $\mathrm{CD} 34^{+}$cells, and subsequently by the $\mathrm{CD} 33^{+}$progeny of these cells which grow exponentially within the first few days post-transplant. This second phase of differentiating veto cells also includes CD11c+ immature dendritic cells and other graft

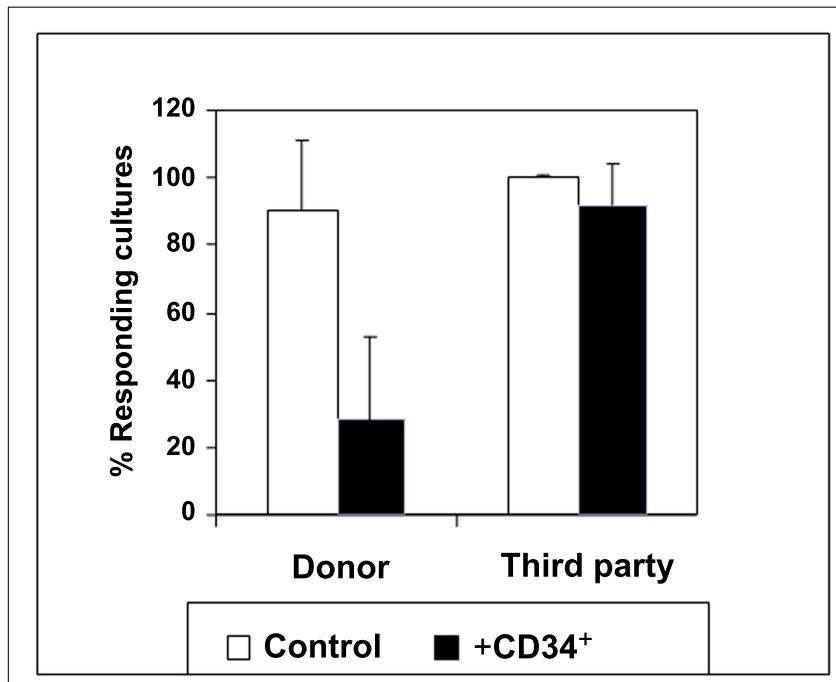

FIGURE 1 (The regulatory activity of CD34 cells: evidence for target specificity. The average CTL response (SD) in the presence (black bars) or absence (white bars) of $\mathrm{CD}_{3}{ }^{+}$cells at a veto-to-responder cell ratio of 0.5 . The veto effect was tested by a limiting dilution assay as follows: Equal numbers $\left(1 \times 10^{6} / \mathrm{ml}\right)$ of responder cells and irradiated allogeneic stimulator cells from the donor of the CD34 cells and a third-party donor were co-cultured for 5 days. The responder cells were then cultured again for 7 days under limiting dilution, and the CTL activity was determined by ${ }^{51} \mathrm{Cr}$-release assay. Data represent the average \pm SD of 11 independent experiments using different donor and third-party pairs. A significant difference ( $p<0.001$ on $t$-test compared with control cultures without CD34 cells) between control cultures and those including CD34 cells was found upon stimulation against donor cells (Rachamim et al., 1998).

facilitating cells. Clearly, the number of all these tolerizing cell types emerging after transplantation is proportional to the number of $\mathrm{CD} 34^{+}$cells infused. The increased engraftment of megadose of HSCT is therefore greatly dependent not only on the ability of the initial inoculums of the $\mathrm{CD} 34^{+}$cells to veto antidonor $\mathrm{T}$ cells, but also on their ability to seed the BM and to generate as rapidly as possible the second or third derivatives which are required to complete the eradication of host anti-donor T cells.

\section{THE USE OF VETO CD8 ${ }^{+}$CTLS IN HSCT}

As described above, the use of purified megadose of $\mathrm{CD} 34^{+}$ HSCT has enabled haploidentical transplantation in leukemia patients and was the first demonstration of the potent clinical potential of donor veto cells. However, this approach is currently limited to supra-lethal myeloablative and highly immunosuppressive conditioning protocols (Martelli et al., 2002). Indeed, studies in non-human primates revealed that any significant reduction of the conditioning, to levels acceptable for elderly patients or for patients with non-malignant disorders, would require veto inducing $\mathrm{CD}^{+} 4^{+}$stem cell numbers which cannot be realistically collected from human donors (Gan et al., unpublished results). Therefore, other populations of veto cells could have a crucial role in supporting and promoting successful engraftment of purified stem cell transplantation under relatively safer RIC. 
As outlined above, $\mathrm{CD} 8^{+}$CTLs were shown in vitro to exhibit the strongest veto reactivity (Reich-Zeliger et al., 2004a). Previous insights on the veto mechanism of $\mathrm{CD}^{+}{ }^{+}$veto CTLs, combining anti-CD8 blockade and FasL-mutated veto cells, have suggested that co-expression of CD8 and FasL is required for the veto activity of these cells (Reich-Zeliger et al., 2000, 2004b). Such a mechanism involves initial recognition of the veto cell by the TCR of the effector $\mathrm{T}$ cells, leading to expression of Fas by the effector $\mathrm{T}$ cell upon activation, and thereby enabling Fas-FasL mediated apoptosis to take place, once inhibitory molecules such as FLICEinhibitory protein (FLIP) are down regulated in the effector cell (Reisner et al., 2006). In addition, the interaction between CD8 on veto CTL and the MHC class I alpha3 domain on the effector cell, is associated with phosphorylation of MEK/ERK in the latter cell, and with a significant reduction of X-linked inhibitor of apoptosis protein (XIAP) levels which, in turn, enables even more potent triggering of Fas-FasL mediated apoptosis in the recognizing effector cell (Scheme 1; Reich-Zeliger et al., 2010). More recent results have indicated that veto activity exhibited by CTLs can also be mediated by an additional perforin based mechanism (Milstein et al., 2010). However, despite their potent veto activity, $\mathrm{CD}^{+}$CTLs cannot be used for "safe" tolerance induction in allogeneic HSCT because of their marked GVH reactivity.

One approach for generating veto CTLs with reduced GVHD reactivity has been described by a series of studies by D. H. Fowler (Fowler and Gress, 2000; Erdmann et al., 2004; Mariotti et al., 2008).

In these studies, it was demonstrated that by using CD3/CD28 particles under IL-2-, IL-7-, and IL-4-containing medium, veto CTLs with Tc2 phenotype can be generated. These cells were shown to abrogate murine BM rejection with reduced GVHD.

We have previously described an alternative approach to generate CTLs with highly reduced GVH reactivity by means of stimulation against third-party stimulators in the absence of exogenous cytokines, followed by further ex vivo expansion using third-party stimulators and IL-2 (Bachar-Lustig et al., 2003). This approach was based on the observation that only activated CTLp are capable of surviving the cytokine deprivation in the primary culture, and that these anti-third-party clones further expand throughout the culture. These anti-third-party CTLs indeed were shown to be depleted of GVHD while supporting BM engraftment in murine models. In accordance with the veto concept, this tolerizing effect of the CTLs was found to be H-2 specific. Thus, a CTL line originating from a strain other than that of the BM donor failed to prevent graft rejection (Bachar-Lustig et al., 2003). Importantly, anti-third-party veto CTLs, upon adoptive transfer into TDBMT recipient mice, were shown to eliminate not only host anti-donor naïve cells, but also host anti-donor memory cells (Reich-Zeliger et al., 2007). Memory $\mathrm{T}$ cells, derived from prior exposure to alloantigen or generated by heterologous immunity or lymphopenia-induced proliferation, are believed to be an important part of the barrier preventing the translation of tolerance induction protocols from inbred rodent strains to the clinic (Pantenburg et al., 2002; Adams et al., 2003; Wu etal., 2004). Therefore, the ability of veto CTLs to overcome memory T cells-mediated rejection could

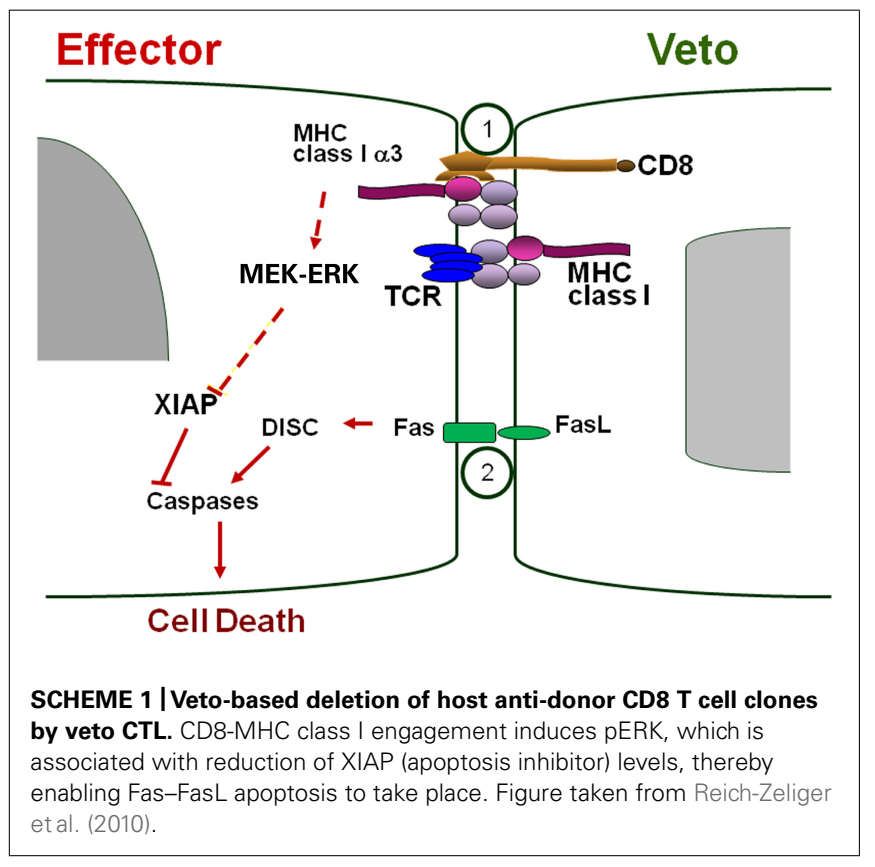

be highly important for their action in clinical settings. Furthermore, a recent study of Nguyen and Geiger (2010) propose that veto CTL can also effectively promote B cell tolerance. Thus, in this study the authors demonstrated that murine CD8 ${ }^{+}$ CTLs, in addition to their renowned veto activity upon recognizing $\mathrm{T}$ cells, can also induce Ag-specific elimination of recognizing $\mathrm{B}$ cells, both in vitro and in vivo and thus veto CTLs may selectively overcome both cellular and humoral graft rejection.

Nevertheless, despite all these important attributes of the veto $\mathrm{CD}^{+}$CTLs, their in vivo activity was shown to be markedly inferior compared to that exhibited in vitro, requiring the administration of large number of CTLs in conjunction with the immunosuppressive drug rapamycin in order to efficiently overcome TDBMT rejection in murine models (Bachar-Lustig et al., 2003). The discrepancy between the CTLs veto activity in vitro and in vivo could be explained when considering two limitations of the veto cells: first, the veto activity is mediated through cell to cell contact and, second, host $\mathrm{T}$ cells are prone to veto mainly in a window of opportunity of up to $48 \mathrm{~h}$ after their activation, thus, once these host $\mathrm{T}$ cells develop into mature effector T cells, veto cells can no longer exert their effect (Anderson and Zimring, 2006). Therefore, while in vitro the veto CTLs are directly plated with their cognate targets, upon infusion in vivo the veto CTLs need to co-localize with the host $\mathrm{T}$ cells within the first $48 \mathrm{~h}$ of the rejection process, or else their effect will be hampered. Indeed, we recently demonstrated that CTLs attained upon long ex vivo culture in the presence of IL-2 exhibit a migration pattern different from the one displayed by naive host $\mathrm{T}$ cells thereby precluding their colocalization. Thus, while naïve host $\mathrm{T}$ cells home efficiently to the lymph nodes (LNs) of BMT recipient mice, the veto CTLs are excluded from the LNs and tend to localize in peripheral sites (Ophir et al., 2010). 


\section{CD8 $^{+}$T CELLS WITH CENTRAL MEMORY PHENOTYPE FOR INDUCING POTENT IN VIVO VETO ACTIVITY}

In order to improve the LNs homing potential of anti-thirdparty $\mathrm{CD}^{+}$veto cells we developed a new protocol, using IL-15, that favor the induction of central memory phenotype in anti-third-pary $\mathrm{CD}^{+} \mathrm{T}$ cells (Ophir et al., 2010). Central memory T cells $(\mathrm{Tcm})$ express the LN homing receptors CD62L and CCR7 (Sallusto et al., 1999) and similarly to naive T cells, localize to the $\mathrm{T}$ cell area of all secondary lymphoid organs (Weninger et al., 2001). Indeed, we demonstrated that these ex vivo induced anti-third-party $\mathrm{Tcm}$, in contrast to anti-third-party CTLs, home to LNs of BMT recipients, where they co-localize with the recipient's endogenous host $\mathrm{T}$ cells. Moreover, the $\mathrm{Tcm}$ displayed strong proliferation at the early post-transplant period and subsequently persisted in vivo for more than 1 year post-BMT, in line with their memory phenotype (Ophir et al., 2010). Most importantly, we demonstrated that Tcm derived from (host $\times$ donor)F1 mice can specifically and efficiently delete in vivo host TCR-transgenic $\mathrm{T}$ cells carrying a TCR transgene with anti-donor specificity. In accordance with the veto concept, this efficient in vivo deletion of anti-donor host $\mathrm{T}$ cells, found to be mediated by apoptosis, did not occur when "non-specific" Tcm, not expressing the donor H-2 haplotype, were used (Figure 2). Thus, murine Tcm perform in vivo veto activity, efficiently deleting host $\mathrm{T}$ cells only when the host $\mathrm{T}$ cells recognize antigens on the $\mathrm{Tcm}$, and not by a non-specific general immunosuppressive effect. Taken together, all these attributes of the Tcm were shown to translate into improved efficacy in overcoming $\mathrm{T}$ cell mediated rejection of murine TDBMT, thereby enabling high survival rate and long-term donor chimerism, without causing GVHD. Thus, adoptive transfer of anti-third-party $\mathrm{Tcm}$, in the absence of rapamycin treatment significantly abolished host $\mathrm{T}$ cells-mediated rejection of fully mismatched Nude-BM. This is in sharp contrast to anti-third-party CTLs, which fail to enable engraftment unless administered in higher numbers and in conjunction with rapamycin treatment (Bachar-Lustig et al., 2003;
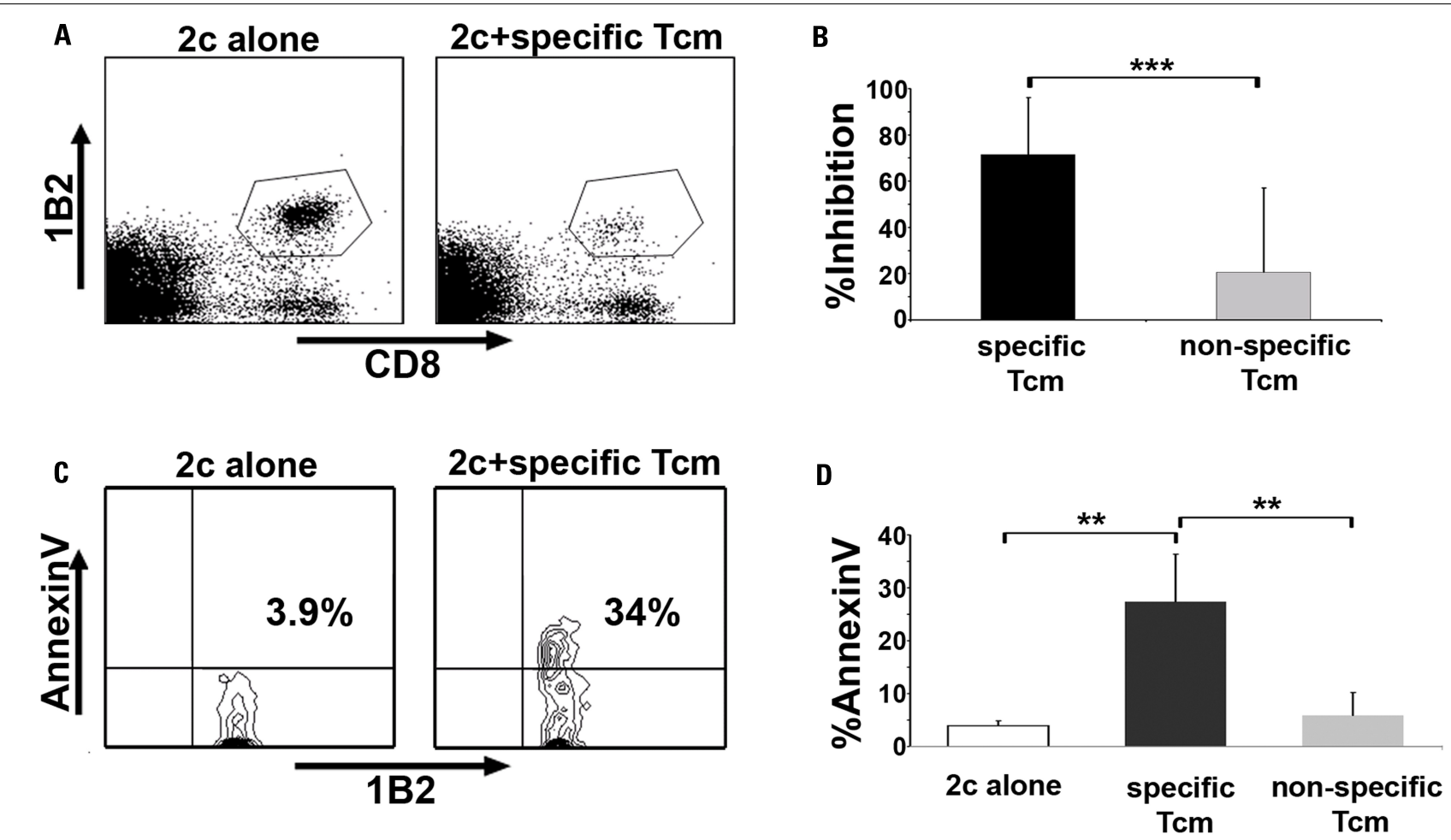

FIGURE 2 | Anti-third-party Tcm are endowed with potent in vivo veto activity. $(\mathbf{A}, \mathbf{B})$ Lethally irradiated $\mathrm{C} 57 \mathrm{BL} / 6\left(\mathrm{H}-2^{\mathrm{b}}\right)$ mice received $1 \times 10^{5}$ $\mathrm{CD}^{+}$purified TCR-transgenic $2 \mathrm{c}$ cells (carrying TCR with anti $\mathrm{H}-2^{\mathrm{d}}$ specificity) and $5 \times 10^{5}$ irradiated BALB/c $\left(\mathrm{H}-2^{\mathrm{d}}\right)$ splenocytes. The following day, the mice were transplanted with $1 \times 10^{6}$ C57BL/6-NUDE BM cells or received, in addition, $5 \times 10^{6}$ "specific," derived from CB6 ( $\mathrm{H}-2^{\text {bd }}$, black bars), or "non-specific", derived from C57BL/6 (H-2 ${ }^{\mathrm{b}}$, gray bars) anti-third-party Tcm. Recipients were sacrificed 8 days post-transplant, their spleens were harvested, and the deletion of anti-donor 2c T cells was monitored by FACS. (A) Representative result demonstrating the level of surviving (7AAD ${ }^{-}$) $2 \mathrm{C}$ cells in the absence (left panel, "2c alone") or presence of "specific" Tcm (right panel " $2 c+$ specific Tcm"). (B) Quantification of results demonstrating efficient inhibition of the 2c cells only by "specific" and not by "non-specific" "Tcm." Data represent average \pm SD of percent inhibition from at least 10

animals in each group, pooled from two independent experiments. (C,D) In vivo model was established as in $(\mathbf{A}, \mathbf{B})$, but $5 \times 10^{5}$ purified $\mathrm{CD}^{+} 2 \mathrm{c}$ cells and $2.5 \times 10^{6}$ irradiated BALB/c splenocytes were administrated. Recipients were sacrificed 8 days post-transplant, their spleens were harvested and FACS analysis of Annexin $V$ levels on living (7AAD ${ }^{-}$) $C D 8^{+} 1 B 2+2 c$ cells was conducted. (C) Representative result demonstrating apoptosis induction upon anti-donor 2c cells by the Tcm as evident by Annexin V levels on 2c cells in the absence (left panel, "2c alone") or presence of "specific" Tcm (right panel, " $2 c+$ specific Tcm"). (D) Quantification of results measuring Annexin V levels on the 2c cells following interactions with "specific" and "non-specific" "Tcm." The figure shows that Apoptosis was induced only by the "specific" $\mathrm{Tcm}$. Data present average \pm SD of percent Annexin V levels in at least four animals from each group, in one representative experiment, out of three performed. ${ }^{* *} p<0.01,{ }^{* *} p<0.001$ (Ophir et al., 2010). 
Ophir et al., 2010). We concluded therefore that by generating antithird-party $\mathrm{CD}^{+}$cells with a central memory phenotype we were able to dramatically enhance their tolerizing veto activity in vivo.

\section{TCR-INDEPENDENT KILLING OF MALIGNANT B CELLS BY CD $8+$ VETO CELLS}

A second objective which could be attained by administration of donor-derived activated $\mathrm{CD}_{8}^{+} \mathrm{T}$ cells in the context of HSCT is related to the ability of these cells to control residual hematological malignancies. Considering that GVL is generally associated with GVHD it was surprising that autologous or allogeneic human and murine anti-third-party veto $\mathrm{CD} 8^{+} \mathrm{T}$ cells, markedly depleted of GVH reactivity, exhibit vigorous responses against different $\mathrm{B}$ cell malignancies (Arditti et al., 2005; Lask et al., 2011). The killing of B cell tumors by anti-third-party CTLs was shown to involve a unique TCR-independent two steps mechanism. First, longlasting conjugates are formed between the CTL and the tumor cell. These conjugates are rapidly formed through binding of ICAM1 on tumor cells by LFA-1 expressed on the veto CTL. Second, a slower process of MHC class I-dependent apoptosis is mediated by binding of the MHC class I $\alpha 2 / 3$ constant region on the tumor cells to the CD8 molecule on the CTL membrane (Arditti et al., 2005; Lask et al., 2011). Likewise, recent results from our laboratory indicate that murine anti-third-party veto $\mathrm{Tcm}$ can also efficiently eliminate murine B cell lymphoma in vivo, through a similar TCR-independent mechanism (Lask et al., 2010). Hence, such single agent veto cell therapy has the potential to have a double benefit in the context of HSCT, namely, promoting and supporting HSCT engraftment through specific tolerizing veto activity while mediating effective anti-cancer response, in the absence of GVHD. Translation of this therapy, optimizing protocols for the generation of human anti-third-party $\mathrm{Tcm}$ is now in progress and clinical

\section{REFERENCES}

Adams, A. B., Williams, M. A., Jones, T. R., Shirasugi, N., Durham, M. M., Kaech, S. M., Wherry, E. J., Onami, T., Lanier, J. G., Kokko, K. E., Pearson, T. C., Ahmed, R., and Larsen, C. P. (2003). Heterologous immunity provides a potent barrier to transplantation tolerance. J. Clin. Invest. 111, 1887-1895.

Anderson, K. M., and Zimring, J. C. (2006). Rapamycin prolongs susceptibility of responding $\mathrm{T}$ cells to tolerance induction by $\mathrm{CD}^{+}$veto cells. Transplantation 81, 88-94.

Arditti, F. D., Aviner, S., Dekel, B., Krauthgamer, R., Gan, J., Nagler, A., Tabilio, A., Martelli, M., Berrebi, A., and Reisner, Y. (2005). Eradication of B-CLL by autologous and allogeneic host nonreactive anti-thirdparty CTLs. Blood 105, 3365-3371.

Asiedu, C., Meng, Y., Wang, W., Huang, Z., Contreras, J. L., George, J. F., and Thomas, J. (1999). Immunoregulatory role of CD8alpha in the veto effect. Transplantation 67, 372-380.

Aversa, F., Tabilio, A., Terenzi, A., Velardi, A., Falzetti, F., Giannoni,

evaluation will commence in the near future in patients with $\mathrm{B}$ cell malignancies.

\section{CONCLUDING REMARKS}

Donor derived veto cells represent an attractive and effective modality for the induction of specific tolerance toward donor Ags. This approach has been already demonstrated in patients by using megadose of purified veto $\mathrm{CD} 34^{+}$stem cells, that can overcome the host's residual immunity surviving the myeloablative conditioning and enable engraftment of HSCT across major genetic barriers without the severe threat of GVHD. However, the number of veto $\mathrm{CD} 34^{+}$cells that can be harvested is insufficient for overcoming the large numbers of host $\mathrm{T}$ cells remaining after RIC. Therefore, combining megadose of $\mathrm{CD} 34^{+}$HSCT with other GVHD-depleted veto cells, potentially anti-third-party $\mathrm{CD} 8^{+}$ Tcm, could enable facilitation of engraftment of HSCT under RIC without the adverse complication of GVHD-producing T cells and without the need for deleterious post-transplant GVHD prophylaxis. It is hoped that this approach could extend the use of HSCT to elderly patients with $\mathrm{B}$ cell malignancies who cannot tolerate intensive protocols and to a variety of patients with non-malignant disorders, associated with longer life expectancy, in whom the current TRM associated with HSCT may not be ethically justified. Use of Experimental Animals Statement: All experiments on live vertebrates were performed in accordance with the Weizmann Institutional Animal Care and Use Committee.

\section{ACKNOWLEDGMENTS}

Supported in part by Mrs. Erica Drake; the Legacy Heritage Fund, Fraida Foundation, Kirk Center for Childhood Cancer and Immunological Disorders and Roberto and Renata Ruhman.

Ballen, K. K., and Spitzer, T. R. (2010). The great debate: haploidentical or cord blood transplant. Bone Marrow Transplant. 46, 323-329.

Chrobak, P., and Gress, R. E. (2001). Veto activity of activated bone marrow does not require perforin and Fas ligand. Cell. Immunol. 208, 80-87.

Claesson, M. H., and Miller, R. G. (1989). Functional heterogeneity in allospecific cytotoxic T lymphocyte clones. III. Direct correlation between development of syngeneic cytotoxicity and loss of veto activity; implications for the mechanism of veto action. Scand. J. Immunol. 29 493-497.

Claesson, M. H., and Miller, R. G. (1984). Functional heterogeneity in allospecific cytotoxic $\mathrm{T}$ lymphocyte clones. I. CTL clones express strong anti-self suppressive activity. J. Exp. Med. 160, 1702-1716.

Claesson, M. H., and Ropke, C. (1986). Antiself suppressive (veto) activity of responder cells in mixed lymphocyte cultures. Curr. Top. Microbiol. Immunol. 126, 213-223.
Clement, A., Pereboev, A., Curiel, D. T., Dong, S. S., Hutchings, A., and Thomas, J. M. (2002). Converting nonhuman primate dendritic cells into potent antigen-specific cellular immunosuppressants by genetic modification. Immunol. Res. 26, 297-302.

Erdmann, A. A., Jung, U., Foley, J. E., Toda, Y., and Fowler, D. H. (2004). Co-stimulated/Tc2 cells abrogate murine marrow graft rejection. Biol. Blood Marrow Transplant. 10, 604-613.

Fink, P. J., Rammensee, H. G., Benedetto, J. D., Staerz, U. D., Lefrancois, L., and Bevan, M. J. (1984). Studies on the mechanism of suppression of primary cytotoxic responses by cloned cytotoxic T lymphocytes. J. Immunol. 133, 1769-1774.

Fowler, D. H., and Gress, R. E. (2000). Th2 and Tc2 cells in the regulation of GVHD, GVL, and graft rejection: considerations for the allogeneic transplantation therapy of leukemia and lymphoma. Leuk. Lymphoma 38, 221-234.

Gale, R. P., and Reisner, Y. (1986). Graft rejection and graft-versus-host 
disease: mirror images. Lancet, 1, 1468-1470.

Gur, H., Krauthgamer, R., BacharLustig, E., Katchman, H., ArbelGoren, R., Berrebi, A., Klein, T., Nagler, A., Tabilio, A., Martelli, M. F., and Reisner, Y. (2005). Immune regulatory activity of $\mathrm{CD} 34^{+}$progenitor cells: evidence for a deletion-based mechanism mediated by TNF-alpha. Blood 105, 2585-2593.

Gur, H., Krauthgamer, R., Berrebi, A., Klein, T., Nagler, A., Tabilio, A., Martelli, M. F., and Reisner, Y. (2002). Tolerance induction by megadose hematopoietic progenitor cells: expansion of veto cells by short-term culture of purified human CD34(+) cells. Blood 99, 4174-4181.

Gyurkocza, B., Rezvani, A., and Storb, R. F. (2010). Allogeneic hematopoietic cell transplantation: the state of the art. Expert Rev. Hematol. 3, 285-299.

Kawai, T., Cosimi, A. B., Spitzer, T. R., Tolkoff-Rubin, N., Suthanthiran, M., Saidman, S. L., Shaffer, J., Preffer, F. I., Ding, R., Sharma, V., Fishman, J. A., Dey, B., Ko, D. S., Hertl, M., Goes, N. B., Wong, W., Williams, W. W. Jr., Colvin, R. B., Sykes, M., and Sachs, D. H. (2008). HLA-mismatched renal transplantation without maintenance immunosuppression. N. Engl. J. Med. 358, 353-361.

Kernan, N. A., Flomenberg, N., Dupont, B., and O'Reilly, R. J. (1987). Graft rejection in recipients of T-cell-depleted HLA-nonidentical marrow transplants for leukemia. Identification of host-derived antidonor allocytotoxic T lymphocytes. Transplantation 43, 842-847.

Lask, A., Goichberg, P., Cohen, A., Goren-Arbel, R., Milstein, O., Aviner, S., Feine, I., Ophir, E., ReichZeliger, S., Hagin, D., Klein, T., Nagler, A., Berrebi, A., and Reisner, Y. (2011). TCR-independent killing of B cell malignancies by anti-thirdparty CTLs: the critical role of MHCCD8 engagement. J Immunol. 187, 2006-2014.

Lask, A., Ophir, E., Or-Geva, N., Cohen, A., Afik, R., Eidelstein, Y., Negrin, R. S., Nagler, A., Berrebi, A., Hagin, D., and Reisner, Y. (2010). Ex vivo generated donor central memory CD8 T cells, previously shown to enhance engraftment of allogeneic bone marrow, also exhibit significant GVL activity without causing Gvhd in an in vivo b cell lymphoma model. Blood 116, a424 (ASH Annual Meeting Abstracts).

Mariotti, J., Foley, J., Jung, U., Borenstein, T., Kantardzic, N., Han, S., Hanson, J. T., Wong, E., Buxhoeveden, N., Trepel, J. B., Fojo, A.
T., Telford, W., and Fowler, D. H. (2008). Ex vivo rapamycin generates apoptosis-resistant donor Th2 cells that persist in vivo and prevent hemopoietic stem cell graft rejection. J. Immunol. 180, 89-105.

Martelli, M. F., Aversa, F., Bachar-Lustig, E., Velardi, A., Reich-Zelicher, S., Tabilio, A., Gur, H., and Reisner, Y. (2002). Transplants across human leukocyte antigen barriers. Semin. Hematol. 39, 48-56.

Miller, R. G. (1980). An immunological suppressor cell inactivating cytotoxic T-lymphocyte precursor cells recognizing it. Nature 287, 544-546.

Milstein, O., Hagin, D., Lask, A., ReichZeliger, S., Shezan, E., Ophir, E., Eidelstein, Y., Afik, R., Antebi, Y. E., Dustin, M. L., and Reisner, Y. (2010). CTLs respond with activation and granule secretion when serving as targets for T-cell recognition. Blood 117, 1042-1052.

Muraoka, S., and Miller, R. G. (1980). Cells in bone marrow and in $\mathrm{T}$ cell colonies grown from bone marrow can suppress generation of cytotoxic $\mathrm{T}$ lymphocytes directed against their self antigens. J. Exp. Med. 152, 54-71. Muraoka, S., and Miller, R. G. (1983). Cells in murine fetal liver and in lymphoid colonies grown from fetal liver can suppress generation of cytotoxic $\mathrm{T}$ lymphocytes directed against their self antigens. J. Immunol. 131, 45-49. Nguyen, P., and Geiger, T. L. (2010). Induction of B-cell immune tolerance by antigen-modified cytotoxic $\mathrm{T}$ lymphocytes. Transplantation 89 , 667-676.

Ophir, E., Eidelstein, Y., Afik, R., BacharLustig, E., and Reisner, Y. (2010). Induction of tolerance to bone marrow allografts by donor-derived host nonreactive ex vivo-induced central memory CD8 T cells. Blood 115, 2095-2104.

Pantenburg, B., Heinzel, F., Das, L., Heeger, P. S., and Valujskikh, A. (2002). T cells primed by Leishmania major infection cross-react with alloantigens and alter the course of allograft rejection. J. Immunol. 169, 3686-3693.

Rachamim, N., Gan, J., Segall, H., Krauthgamer, R., Marcus, H., Berrebi, A., Martelli, M., and Reisner, Y. (1998). Tolerance induction by "megadose" hematopoietic transplants: donor-type human CD34 stem cells induce potent specific reduction of host anti-donor cytotoxic $\mathrm{T}$ lymphocyte precursors in mixed lymphocyte culture. Transplantation 65, 1386-1393.

Reich-Zeliger, S., Bachar-Lustig, E., BarIlan, A., and Reisner, Y. (2007). Tolerance induction in presensitized bone marrow recipients by veto CTLs: effective deletion of host anti-donor memory effector cells. J. Immunol. 179, 6389-6394.

Reich-Zeliger, S., Bachar-Lustig, E. Gan, J., and Reisner, Y. (2004a). Tolerance induction by veto CTLs in the TCR transgenic 2C mouse model. I. Relative reactivity of different veto cells. J. Immunol. 173, 6654-6659.

Reich-Zeliger, S., Gan, J., Bachar-Lustig, E., and Reisner, Y. (2004b). Tolerance induction by veto CTLs in the TCR transgenic 2C mouse model. II. Deletion of effector cells by Fas-Fas ligand apoptosis. J. Immunol. 173, 6660-6666.

Reich-Zeliger, S., Eidelstein, Y., Hagin D., Antebi, Y. E., Seger, R., and Reisner, Y. (2010). Deletion of alloreactive $\mathrm{T}$ cells by veto cytotoxic $\mathrm{T}$ lymphocytes is mediated through extracellular signal-regulated kinase phosphorylation. Transplantation 90 , 380-386.

Reich-Zeliger, S., Zhao, Y., Krauthgamer, R., Bachar-Lustig, E., and Reisner, Y. (2000). Anti-third party $\mathrm{CD}^{+}$CTLs as potent veto cells: coexpression of CD8 and FasL is a prerequisite. Immunity 13, 507-515.

Reisner, Y., and Martelli, M. F. (1995). Bone marrow transplantation across HLA barriers by increasing the number of transplanted cells. Immunol. Today 16, 437-440.

Reisner, Y., Reich-Zeliger, S., and Bachar-Lustig, E. (2006). The role of veto cells in bone marrow transplantation. Curr. Opin. Organ Transplant. 11, 366-372.

Ringden, O., Remberger, M., Svahn, B. M., Barkholt, L., Mattsson, J., Aschan, J., Le Blanc, K., Gustafsson, B., Hassan, Z., Omazic, B., Svenberg, P., Solders, G., von Döbeln, U., Winiarski, J., Ljungman, P., and Malm, G. (2006). Allogeneic hematopoietic stem cell transplantation for inherited disorders: experience in a single center. Transplantation 81, 718-725.

Sallusto, F., Lenig, D., Forster, R., Lipp, M., and Lanzavecchia, A. (1999). Two subsets of memory $\mathrm{T}$ lymphocytes with distinct homing potentials and effector functions. Nature 401, 708-712.

Scandling, J. D., Busque, S., DejbakhshJones, S., Benike, C., Millan, M. T., Shizuru, J. A., Hoppe, R. T., Lowsky, R., Engleman, E. G., and Strober, S. (2008). Tolerance and chimerism after renal and hematopoietic-cell transplantation. N. Engl. J. Med. 358, 362-368.

Seggewiss, R., and Einsele, H (2010). Immune reconstitution after allogeneic transplantation and expanding options for immunomodulation: an update. Blood 115, 3861-3868.

Steward, C. G., and Jarisch, A. (2005) Haemopoietic stem cell transplantation for genetic disorders. Arch. Dis. Child. 90, 1259-1263.

Thomas, J. M., Carver, F. M., Cunningham, P. R., Olson, L. C., and Thomas, F. T. (1991). Kidney allograft tolerance in primates without chronic immunosuppression - the role of veto cells. Transplantation 51, 198-207.

Weninger, W., Crowley, M. A., Manjunath, N., and von Andrian, U. H. (2001). Migratory properties of naive, effector, and memory CD8(+) T cells. J. Exp. Med. 194, 953-966.

Wood, M. L., Orosz, C. G., Gottschalk, R., and Monaco, A. P. (1992). The effect of injection of donor bone marrow on the frequency of donor-reactive CTL in antilymphocyte serum-treated, grafted mice. Transplantation 54, 665-671.

Wu, Z., Bensinger, S. J., Zhang, J., Chen, C., Yuan, X., Huang, X., Markmann, J. F., Kassaee, A., Rosengard, B. R., Hancock, W. W., Sayegh, M. H., and Turka, L. A. (2004). Homeostatic proliferation is a barrier to transplantation tolerance. Nat. Med. 10, 87-92.

Zangi, L., Edelshtein, Y., Klionsky, Y., Bachar-Lustig, E., Shezen, E., ReichZeliger, S., Lask, A., Milstein, O., Shinder, V., and Reisner, Y. (2009). Tolerance induction by immature dendritic cells is mediated by distinct MHC dependent and independent mechanisms: a novel role for perforin, granzyme A and Toll like receptor 7. Blood 114, a65 (ASH Annual Meeting Abstracts).

Conflict of Interest Statement: Yair Reisner is a consultant to Cell Source Ltd.

Received: 23 January 2012; paper pending published: 24 February 2012; accepted: 10 April 2012; published online: 02 May 2012.

Citation: Ophir E and Reisner Y (2012) The use of donor-derived veto cells in hematopoietic stem cell transplantation. Front. Immun. 3:93. doi: 10.3389/ fimmu.2012.00093

This article was submitted to Frontiers in Alloimmunity and Transplantation, a specialty of Frontiers in Immunology. Copyright (C) 2012 Ophir and Reisner. This is an open-access article distributed under the terms of the Creative Commons Attribution Non Commercial License, which permits non-commercial use, distribution, and reproduction in other forums, provided the original authors and source are credited. 